\title{
Contemplation and new lifestyles (or how to promote your personal development from a hospital bed)
}

\section{Mario Vatta}

The word contemplation almost always immediately conjures up thoughts of great silences and vast open spaces, or of small, closed environments designed for intense, concentrated thought. The latter settings, often religious, barely furnished and dimly lit, are conducive to introspection and an opening of the soul to positive thoughts, pregnant with the desire for peace, and often goodness.

Contemplative thought is tinged with a certain religiosity that is not necessarily linked to a specific religious denomination but rather to one's own "inner self", which may even be open to the possibility of encountering and discovering the "other" (not always with a small "o"): an encounter rich with novelty, when it comes to desires at least, and therefore just waiting to be discovered. But such discovery, to come about, practically always demands, as a necessary condition, a climate of humility a state of being that is not always easy to achieve but that, over time, can be attained, providing one manages to avoid the affectation that is the opposite of the natural, lightly worn humility to which we aspire.

Humility, like the contemplative state, is not something that can be improvised. Humility is a gift that life gives us: a gift to be sought, loved and protected.

Contemplation is possible for those seeking spaces for their soul - those wanting to open up their mind and their heart.

And for all this to be possible, a crucial factor is place, which is to be understood not only in a physical sense. Being "in the right place" means being in a conducive atmosphere, and this necessary condition can manifest itself at the most unexpected times: the language of the spirit comes not so much from that which surrounds us as from within.

It may seem strange - and I am the first to admit this that during an illness, requiring a stay in hospital, the need for spaces, opportunities and resonances can, timidly but definitively, be satisfied.

Musing to myself one day, during one of my frequent hospital stays, I was struck by the rather obvious thought that patients, being in a supine position, must inevitably "look upwards". Jesting aside, there can be no denying that for those who are in hospital, time becomes all important and assumes connotations that make it diametrically opposed to time as perceived "by those who are healthy and free". Time seems endless, especially at night. The long silent nights when sleep eludes us - and our surprisingly lucid mind wanders and will not be stilled - are filled with questions about what tomorrow will bring.

In this undesired situation, with its unfamiliar environment and web of terms belonging to a language of technical jargon, we become gripped by a kind of confused distress, our gaze shifting from face to face looking for explanations - answers even - to the questions inevitably thrown up by the new development that is our illness. Added to all this there are the routine actions and rituals dictated by a protocol whose existence had previously been quite unknown to us.

Unfamiliar acronyms and abbreviations referring to as many clinical tests serve as a reminder that, within the hospital setting, professional expertise, undeniable and tangible, is being devoted to tackling our current illness. The aim - and we realise this as the days unfold - is to bring about a recovery, or a return to health, that, if it is to become established, will almost always require us to make changes to our lifestyle. But this situation can also place us in the role of spectators, as it reminds us of TV shows like "ER" which feature gleaming emergency rooms where life is always frenetic, frenzied even, but where, in the midst of all the dramatic chaos, our "heroes always come through in the end!".

The moments of silence, spent reflecting upon or summarising what we have heard, will see us reasoning about about the more or less dramatic paths that have led us to entrust ourselves - not without some "defensive" reservations - to these "guardians of health".

Finally, the first hours following the start of our care in a hospital setting see our emotions swinging between moments of confidence and moments of distress. We ask ourselves how long we are going to be kept in for, and the need for the hospital stay seems to pale into insignificance as we are assailed by thoughts about all the "outside" commitments and engagements that our condition has put a sudden and absolute stop to, even though it would undoubtedly be better, as far as possible, not to overestimate the importance of these.

This point is the start of our ascent, sometimes difficult, towards our own recovery - our pursuit of a possible and at the same time necessary state of wellbeing.

From "contemplators in disease", we are no able, day by day, to transform ourselves into "collaborators in the pursuit of health". We may even manage, individually, to turn our hospital stay into an opportunity for personal growth.

As inpatients we have a chance to rediscover (is this what contemplation is all about?) realities that we had perhaps relegated to the background, if not forgotten, and this, as the days go by, will allow us to accept and adjust our lives, and re-establish relationships on the basis of new standards - those regulating an existence characterised by greater sensitivity to things that matter, mainly because it is the result of an approach shared by people who, seeking a form of interaction based on the exchanging of experiences, really do see each other. At this point, we might legitimately wonder whether, in 
order to explain all this, it was really necessary, in the opening remarks, to "abuse" the term contemplation (borrowed from experiences of a religious or even ascetic/mystical nature) and the whole reality it represents.

In arguing a point, unless we are referring to scientific theories that are, by definition, "exact", one will inevitably almost always draw on and make reference to one's own life and experiences.

Paradoxically perhaps, I like to count my numerous hospital stays as opportunities I have been given to withdraw into myself and "take stock so as to be able to start out afresh". If we have the ability to mentally review thoughts and situations, to go back over facts and events, and to imagine (this is a very important aspect), with strength, confidence and above a real will to live, that which comes "after" - an "overhauled" condition certainly, but always one stemming from conscious paths leading towards renewed wellbeing - then this will allow us to re-construct a life in which the many situations that have been wrongfully neglected will gain renewed importance and provide us with a context in which we can, "in newness of life", approach people, feelings and friendships, as well as commitments and responsibilities, in a fresh light - cautious but trusting, and in a manner that is more sensitive, precisely because it is more human.

For those who are accustomed to referring to and trusting in God and His paternal providence, it will be a continuous rediscovery of the great gift of life.

These are things that can occur during a hospital stay, in other words in a setting that, even though it does not offer great silences or vast spaces, provides a perfect opportunity for reflection.
The "fortune" (!?!) of those who manage to approach a hospital stay with intelligence and a sense of responsibility lies precisely in the fact that this attitude enables them to realise that certain things that they had relegated to the background exist, or still exist. The intervention of therapists is designed along these very lines: and once we have been put back on our feet - healed or partially "restored" - it is up to us to resume our journey according to new parameters. To live, not just mechanically, but to really breathe. To live in the knowledge that every day, alongside our commitments and responsibilities, the sun rises, nature has something to tell us, and men and women - our fellow human beings - are living and, in the course of their shared journey, interacting with each other to give real meaning to their lives. "For this to happen - as I pointed out some time ago we need to treat the city as a friend ... Being willing to share the joys, hopes and concerns of those who live with us in this beautiful place can mean that moments of isolation, devoted to reflection and prayer, continue to be, for all those who, through prayer, are able to enter into contact with God and talk to Him of those we love and for whom we wish inner peace and a better future, the dimension for contemplating, giving thanks and praying".

On our discharge from hospital we find ourselves picking up the threads of everyday life with a touch more wisdom and a real sense of gratitude towards the group of men and women who, in caring for us, have restored us - at least partially - to health, and in so doing have given us back the joy of living to discover even the small and simple things of life.

The very things that continue to give meaning to our existence.

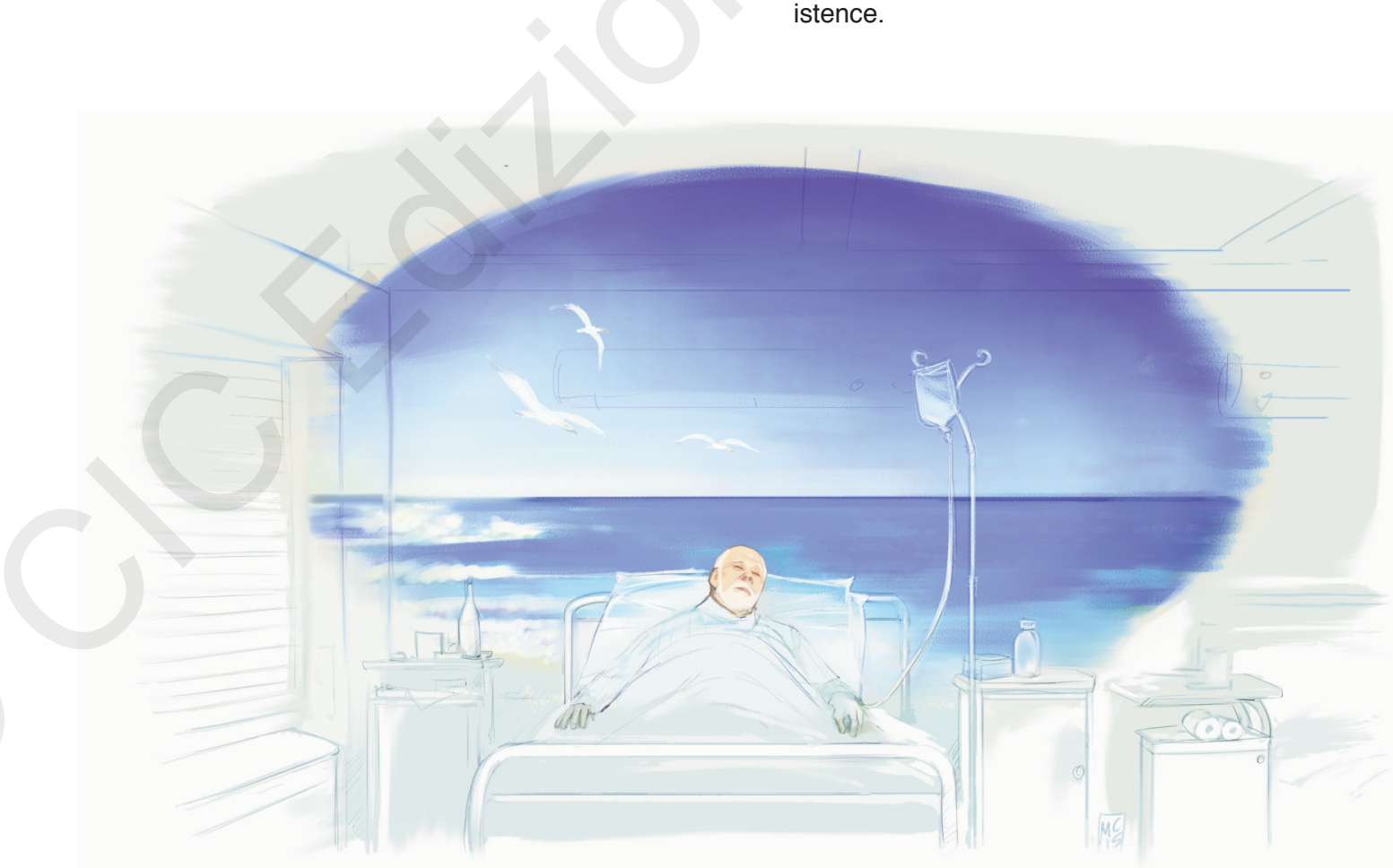

illustration by Marco Ceruti 


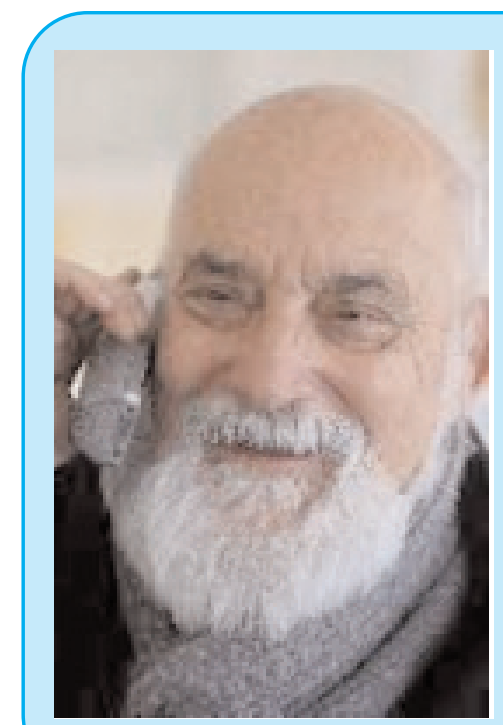

Mario Vatta is a Catholic priest and founder of the "Saint Martin in the Fields" (San Martino al Campo) community in Trieste (Italy) that, for decades, has offered hospitality, a listening ear and work to people who find themselves in difficulty for various reasons (the mentally ill, former prisoners, the homeless, and so on). Vatta regularly writes a weekly column for the newspaper of Trieste, "Il Piccolo", which provided the source for this article which sets out his reflections during one of the many periods he has spent hospital due to heart problems. Mario Vatta has published several books. These include: "Buona Domenica. Trieste volti e storie" , "Il cammino accanto. Ancora Buona Domenica", "Un mosaico di fiducia", "Sa wada, sa wada, fada", "L'anello al dito. Una vita sulla strada", and "Lo sguardo lontano". Vatta's books are collections of short writings stemming from sensations, events and stories (nearly all with a small "s") that he collects, annotates and narrates as short and simple tales of everyday life. Sometimes the events and people he relates may seem insignificant, at least to those who are used to extraordinary tales whose protagonists have to be incredible figures and in which the storytelling is almost more important than the story and the real people it concerns. Mario Vatta invites the reader to look beyond all this, but at the same time to pay closer attention to inner lives. 